\title{
VOORKOMEN EN VERSPREIDING DER ZOOGDIEREN IN DE NOORDOOSTPOLDER
}

\author{
DOOR \\ DR. K. W. DAMMERMAN \\ Rijksmuseum van Natuurlijke Historie, Leiden
}

Ofschoon een systematisch onderzoek naar het voorkomen en de verspreiding van zoogdieren in de Noordoostpolder niet heeft plaats gevonden, zijn de gegevens daarover, die in de afgelopen jaren bekend zijn geworden, toch wel van voldoende belang om in een publicatie vast te leggen.

Over de zoogdierfauna van Urk en Schokland vóór de drooglegging staan ons maar zeer spaarzame opgaven ter beschikking. Schokland wend in 1933 door Utrechtse biologen bezocht en volgens mededeling van de heer M. F. MöRZER BRUYNS werden toen in de omgeving van Middelbuurt huismuizen. en bruine ratten aangetroffen. In I940 is de heer Mörzer BRUYNS begonnen met een hernieuwd onderzoek naar de zoogdierbevolking van Schokland en de N. O. polder, maar na het voorjaar. 194I kon hij zich hiermede niet meer bezig houden. De door hem bijeengebrachte gegevens zijn helaas niet vastgelegd; de heer Mörzer Bruyns was echter zo welwillend mij hieromtrent enige schriftelijke mededeling te doen, terwijl de door hem verkregen resultaten ook voor een deel zijn gepubliceerd door Mej. Dr. A. Schreuder 1 ).

In 1940 waren de huismuizen op Schokland mogelijk nog aanwezig, bruine ratten werden niet meer gezien. De Noordse woelmuis was toen en ook vroeger uiterst algemeen op het eiland. Uit braakballen van uilen kwamen ook nog resten van bosmuizen en huisspitsmuis te voorschijn.

Van de zoogdieren, die op Urk voorkwamen, zijn we nog minder goed op de hoogte. Volgens de bewoners waren bruine ratten op het haventerrein en huismuizen in de woningen en pakhuizen te vinden, ook toen Urk nog eiland was. Veldmuizen of woelmuizen waren er niet bekend en vermoedelijk ontbraken deze ook; bij ons bezoek in Juli 1942 hebben wij ze dan ook niet kunnen ontdekken.

Na Mörzer BruYns hebben zich aan het faunistisch onderzoek van de N. O. polder nog gewijd de heren I. Kristensen, i94I-'43, J. H. Muller,

1) Zoologische Mededeelingen XXV, 1945, p. 239. 
I943, en D. W. Langeveld, I944-'45. Speciale aandacht aan zoogdieren is door hen evenwel niet besteed; wel zijn in de door hen uitgebrachte rapporten gegevens daarover te vinden en ook werd in enkele gevallen materiaal verzameld. Door Dr. Feekes, toentertijd hoofd van het Plantkundig Laboratorium van de N. O. polderwerken te Kampen, zijn toen de door hemzelf en anderen verrichte waarnemingen, tot en met I943, op een kaart uitgezet. Deze gegevens zijn niet alle even bruikbaar, zo de opgaven over „muizen”, ,ratten” en ,spitsmuizen", waarbij geen onderscheid wordt gemaakt tussen de verschillende soorten. Met „ratten" zal in het algemeen bruine ratten zijn bedoeld, terwijl in het geval van „spitsmuizen" wel veelal de gewone bosspitsmuis zal zijn waargenomen. In vele twijfelgevallen blijven dergelijke opgaven toch onzeker.

Wij zelf hebben bij onze bezoeken aan de polder ook steeds gegevens of materiaal van zoogdieren verzameld, wanneer daartoe gelegenheid bestond; in 1944 en ' 45 bleef het onderzoek door de oorlogsomstandigheden grotendeels liggen; ook na de bevrijding kon door gebrek aan transportmiddelen de polder niet bezocht worden. In Augustus 1946 is een vragenlijst aan alle bedrijven in de polder toegezonden, teneinde een overzicht van de zoogdierenstand te verkrijgen. Het spreekt vanzelf, dat ook hierbij slechts enigszins betrouwbare opgaven waren te verwachten omtrent de goed bekende en gemakkelijk te herkennen dieren. Tegelijkertijd werd vermeld, dat toezending van braakballen van uilen en roofvogels op prijs zou worden gesteld. Naar aanleiding van dit laatste verzoek is evenwel geen enkele inzending binnengekomen.

Wel werd een groot aantal braakballen van ransuilen verzameld door Dr. TÉn Kate uit Kampen, in Maart 1945, op kavel $Q$ 123 (tegen de dijk aan het Zwarte Meer tussen Kadoelen en Ramspol), terwijl in Augustus I946 enige velduilproppen binnenkwamen van kavel J 94 (in de hoek waar de Zuidervaart in de Urkervaart uitkomt).

Dit materiaal werd onderzocht door Mej. Schreuder. In de ransuilproppen werden aangetroffen: I99 veldmuizen, 3 bosmuizen en I dwergmuis; in de velduilproppen: 3 veldmuizen, I Noordse woelmuis, 2 dwergmuizen en I bosspitsmuis.

Enige algemene opmerkingen over het verloop van de zoogdierenstand in de N. O. polder mogen hier volgen.

Zodra het land langs de kust van Overijssel en Friesland droog viel, in I94I, kwamen hier veldmuizen de polder binnen; tegelijkertijd verspreidde zich van Schokland uit de daar voorkomende Noordse woelmuis. Veldmuizen bevolkten ook al spoedig de dijk Kadoelen-Ramspol. Ook Noordse woelmuizen vestigden zich op de dijk ten Zuiden van Schokland. Het is niet waarschijnlijk, dat laatstgenoemde soort ook vanuit het vasteland de polder is binnengekomen, al is zij ook van Zuid-Friesland en de Kop van Overijssel bekend. Vooreerst was het land, dat het eerst droog viel, langs de kust en het Kamperzand, zanderig en betrof het hier de hoogst gelegen gronden, die het minst 
vochtig bleven, terrein dus meer geëigend voor de veldmuis dan voor de vochtminnende Noordse woelmuis. Verder zijn ons uit dit oostelijkste deel van de polder tot en met Ramspol in 1942 en ook later uitsluitend veldmuizen in handen gekomen.

In 1943 breidt de veldmuis zich dan zeer snel uit over het gehele oostelijke deel van de N. O. polder, bereikt dan ook Schokland, en wordt met zekerheid reeds vastgesteld op kavel $\mathrm{J} 40$ (Aug. I943), nog een eind voorbij het kamp Nagele. Op de dijk Schokkerhaven-Urk-Lemmer worden nu vele muizen gezien, zowel veldmuizen als Noordse woelmuizen. De veldmuis heeft waarschijnlijk ook van het Noorden uit de dijk bezet.

Het westelijk onontgonnen deel van de polder, dat zeer drassig is en dikwijls nog gedeeltelijk onder water staat, is een ideaal terrein voor de Noordse woelmuis, maar toch dringt ook hier de veldmuis snel door en neemt de hoger gelegen gronden en bulten in beslag. In het in cultuur gebrachte gebied heerst uitsluitend de veldmuis. Het is te verwachten, dat op de duur de veldmuis de Noordse woelmuis zal verdringen; de laatste zal alleen op zeer vochtige plaatsen of in kwelgebieden stand houden. Ook op Schokland, dat thans van extreem vochtig extreem droog is geworden, zullen ze waarschijnlijk verdwijnen.

Andere soorten muizen blijven ver in de minderheid, behalve de dwergmuis, die in de geweldige rietvelden in het westelijk gedeelte van de polder zeer gunstig terrein vindt.

Roofdieren, zoals bunzing, wezel en hermelijn, volgen de muizen overal op de voet.

Merkwaardig is ook de snelle verbreiding van huismuis en bruine rat. Overal waar een schuur, een opslagplaats of een boerderij wordt gevestigd, verschijnen deze dieren vrijwel onmiddellijk, ondanks het feit dat de boerderijen nog gemiddeld $\mathrm{I}, 5$ tot $2 \mathrm{~km}$ van elkaar verwijderd zijn. Bruine ratten werden reeds in 1943 waargenomen midden in de polder, op de plaats waar het toekomstige hoofddorp, Emmeloord, zal komen.

Hazen zijn reeds talrijk, maar het konijn, al is het op enkele plaatsen vastgesteld, zal zich op de zware kleigronden niet thuis voelen.

Hieronder wordt nog voor elke soort afzonderlijk opgegeven, waar en wanneer deze waargenomen werd. Hierbij zij nog opgemerkt, dat bij de secties waarin de polder is verdeeld (A $t / m \mathrm{~T}$, zie kaartje) steeds eerst de secties zijn genoemd, die het dichtst bij het oude land liggen en het laatst de het verst daarvan verwijderde secties onder de dijk Urk-Lemmer.

\section{Mol (Talpa europaea L.).}

De eerste molshoop werd waargenomen door Kristensen, 30 Augustus I94I, noordelijk van de brug bij Kadoelen. In I942 waargenomen op kavel $\mathrm{T}$ I25, in 1943 op $\mathrm{P} 78$, nabij Ramspol (FeEkes).

Volgens de vragenlijst 1946 worden slechts enkele opgegeven voor de sec- 
lies $K, L, R, M$ en $N$. Allecn op de grens van sectie $R$ en $N$ nabij kavel $N$ 49 zouden er vrij veel voorkomen.

Egel (Erinaceus europaeus L.).

Egels worden slechts sporadisch gemeld. Twee stuks werden waargenomen op kavel Q II8, April 1946. Ook volgens de vragenlijst I946 worden slechts weinig exemplaren gezien: een op erf $R_{79}$, een op kavel $N_{1}$, een op erf Q I 8 .

B os s its mu is (Sorex araneus L.).

Ecn ex. uit de Kuinder buitenpolder, November 1942. Waargenomen in I943 op de meerdijk bij kavel $\mathrm{P} 76$ en op $\mathrm{E} 36$ (FEEKEs). Volgens de enquête I 946 komen spitsmuizen slechts matig voor, in het veld, K 70 en T I I2, langs slootkanten en greppels, $\mathrm{R}$ 43. Eén exemplaar uit velduilprop, J 94, Augustus 1946.

$\mathrm{H}$ u is $\mathrm{s}$ it $\mathrm{s} \mathrm{m}$ is (Crocidura russula Herm.).

De soort was reeds bekend van Schokland voor de drooglegging en werd aldaar uit uilenbraakballen verkregen (MörzER BRUYNS). Een exemplaar van Schokland, I943 (J. H. Muller). FeEkes geeft als waargenomen op NoordSchokland in 1943 een spitsmuis; vermoedelijk betrof het ook hier een huisspitsmuis.

W a ter rat (Arvicola amphibius L.).

Een adult $Q$ gevangen bij het ploegen op kavel $Q$ I23, Juli 1943. Volgens vragenlijst 1946 werden enkele gezien aan de Enservaart, de Marknesservaart en langs tochten op $R 2$.

A a $\mathrm{d} \mathrm{m}$ u is (Microtus agrestis L.).

Komt weinig voor; een $Q$ van kavel E I73, April 1943. Drie exemplaren ( $\sigma^{7,} 2$ Qㅇ) van kavel T 2, 27 April 1944.

$\mathrm{Veld} \mathrm{mu} \mathrm{is} \mathrm{(Microtus} \mathrm{arvalis} \mathrm{Pall.).}$

De meest algemene soort in de N. O. polder. Reeds vroeg, I94I, begint de invasie vanuit het aansluitende land en wordt deze muis gemeld van de oostelijke kuststrook en de dijk Kadoelen-Ramspol (J. H. MulleR). In I942 neemt het aantal steeds toe en worden ook vondsten gedaan binnen de polder: kavel L 59, I $\&$, Nov. I942; Kuinder buitenpolder, I $\sigma^{\circ}$, I $ᄋ$, Nov. I942; M I33, I $\sigma^{\circ}$, Nov. I942; T 39, I \&, Juli I942; Ramspol, 8 . $0^{\circ} 0^{\circ}, 4$ 우, Dec. 1942 .

In 1943 breidt de soort zich sterk uit, niet alleen in het oostelijk deel van de polder met de voortschrijdende ontginning, maar ook op de dijk Schokkerhaven-Urk-Lemmer worden nu veldmuizen gevonden en in het nog onontgonnen westelijk deel, waar ze huizen op hoger terrein en droog blijvende 
bulten in het drassige land. Waarnemingen of materiaal zijn bekend van de kavels: R 28, T 60, M 108, P 31, 39, 49, 64, 93, G 98, H 6, 43, J 38, 40, 70, E I36, C 67, I0I, D I6. Voorts I ơ van Schokland, April 1943.

Ook in 1944 werden exemplaren op tal van plaatsen ingezameld. Uit ransuilproppen, gevonden op Q I23, Maart 1945, komen I99 stuks te voorschijn, uit braakballen van een velduil, J 94, Aug. 1946, 3 stuks. De enquête van 1946

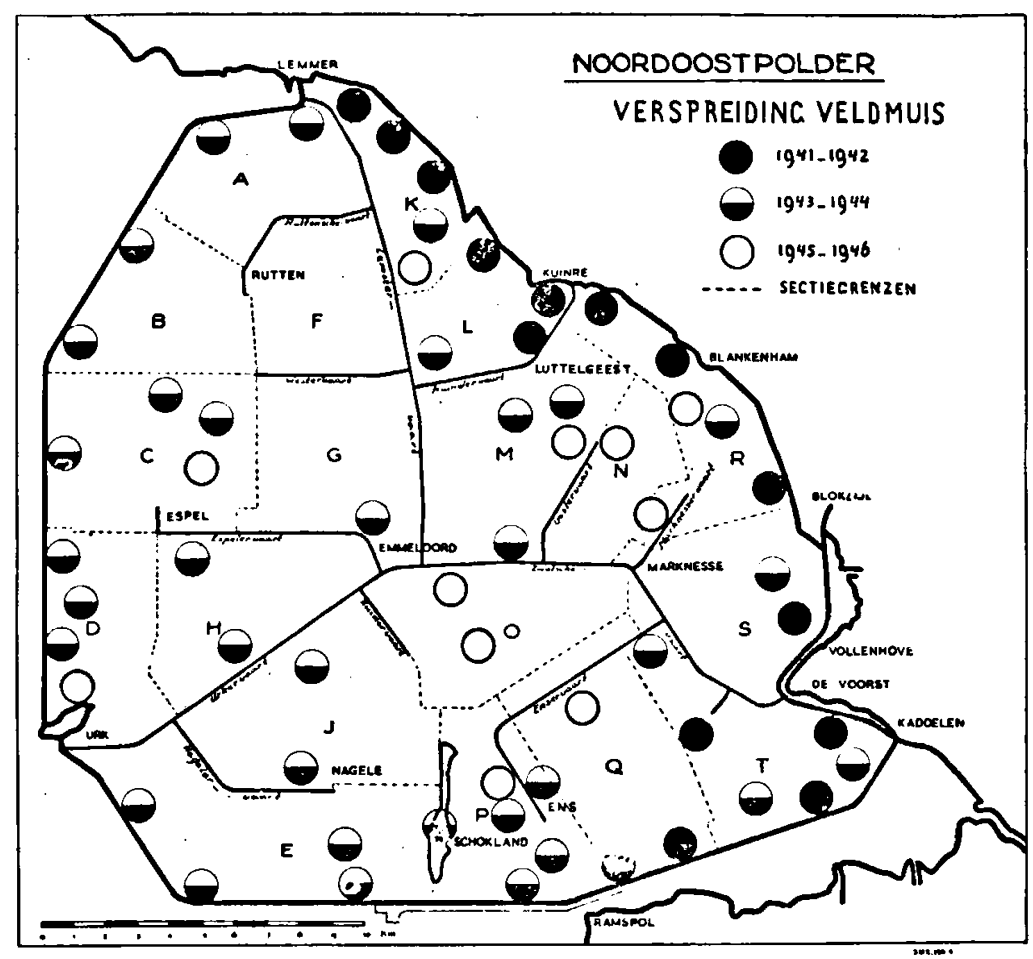

leert, dat veldmuizen overal voorkomen in de secties, waar boerderijen zijn geplaatst; meestal luiden de opgaven: matig of gering, slechts in enkele gevallen is sprake van: tamelijk veel of vrij veel, $R$ I2 en $T$ IO2; veel, $K$ 7o en $\mathrm{P}$ I8; zeer veel, $\mathrm{K}$ i7 en $\mathrm{R}$ 18-23.

Noordse woelmuis (Microtus ratticeps Keys. et Blas.).

Voor de drooglegging was de Noordse woelmuis op Schokland uiterst algemeen. In 1942 kon KRISTENSEN nog in korte tijd 200 exemplaren bijeen brengen, ingezameld door arbeiders. Vanaf het eiland verbreidde de soort zich in de omgeving. Volgens een mededeling van Mörzer Bruyns vestigde deze woelmuis zich ook op de dijk en waren deze dieren hoogstwaarschijnlijk afkomstig van de aangrenzende gebieden van Overijssel, waar de soort eveneens is aangetroffen. Positieve gegevens en materiaal bezitten we slechts van de naaste omgeving van Schokland: 17 ex. van de kavels $\mathrm{P} 23,26,32,33$ en 
E 173. (April-Mei 1943). Het verste punt in de polder vanwaar materiaal werd verkregen is kavel $\mathrm{J}$ 94, waar de Zuidervaart in de Urkervaart uitkomt (I: ex. uit velduilprop, Aug. 1946). Wel werd de soort nog verder in de polder waargenomen, op kavel C 92, Mei I946 (FEEKES), en holen werden door ons gevonden in droge plekken temidden van moerasgebied, D 80-82, in de nabijheid van Urk (Oct. 1946).

In het westelijk onontgonnen gebied van de polder, dat drassig bleef, kreeg de Noordse woelmuis overal kans zich te nestelen; in het oostelijk gedeelte, dat al spoedig in cultuur gebracht is, ontbreekt de soort waarschijnlijk. Uit dit gebied hebben we nimmer een exemplaar gekregen, terwijl ook in de talrijke ransuilproppen, verzameld op $Q$ I23, Maart 1945 , op de 199 daarin aangetroffen veldmuizen geen enkele Noordse woelmuis voorkwam.

$\mathrm{Nu}$ Schokland door de drooglegging en aanzienlijke daling van het grondwater van extreem vochtig extreem droog is geworden, zal de Noordse woelmuis er vermoedelijk niet lang meer stand houden.

B os m is (Apodemus sylvaticus L.).

Is over het algemeen nog weinig vastgesteld. Mörzer BRUYns vond in I940 een dood exemplaar van een jonge bosmuis op de zuidpunt van Schokland. Verondersteld werd, dat het exemplaar daar van elders-was angebracht. Braakballen van het eiland leverden in I94I echter eveneens resten van bosmuizen op. We verkregen verder I adult $\sigma^{\circ}$ van kavel $Q$ iा8, April 1944 en I ex. van kavel P 3I, Aug. I943 (H. J. Muller), terwijl voorts 3 exemplaren werden gevonden in de ransuilproppen van $Q$ I23, Maart 1945.

D we $\mathrm{rgmu}$ is (Micromys minutus Pall.).

Deze soort is weer veel talrijker; bij de opgaven is verwarring met andere soorten ook niet waarschijnlijk. Drie ex. van kavel R 28, Febr. I943; I $Q$ bij dorp C (Ens), Maart I943; I ơ oost van Schokland, April I943; I ơ van kavel P 93, Juni I943 (J. H. Muller) ; I ex. van kavel E I57, Maart 1944; I ex. van kavel F 80, Mei 1944.

In Juli 1944 werd een langwerpig nest (winternest?), in het riet gebouwd, gevonden tussen Schokland en Nagele. Hierin waren 6 . jongen; deze leken echter te groot voor een dwergmuis (lengte $\pm 3 \mathrm{~cm}$, ogen nog gesloten, huidskleur grijs, beharing zwart), ook oren te groot. Mogelijk waren het jongen van een bosmuis, die dit nest in beslag had genomen. Nesten van dwergmuizen zijn voorts nog waargenomen op kavel D 29, Juli I946 (FEEKES); nest met onbehaarde jongen op D 89, Oct. 1946 (BOER); een nest onder oude pan, keileemreservaat noord van Urk, Oct. 1946.

In de braakballen van ransuilen, van $Q$ I23, werd I ex., in de velduilproppen van J 94 werden 2 ex. aangetroffen.

De vragenlijst van 1946 vermeldt de soort als matig tot zeer veel voorkomend; volgens A. C. BOER komt de dwergmuis veel voor, doch sterft uit; men vindt veel dode. 
Z warte $\mathrm{R}$ at (Rattus rattus L.).

Komt waarschijnlijk in de polder nog niet voor. Bij de vragenlijst 1946 worden ze wel een enkele keer vermeld, maar vermoedelijk werden ze verward met de eveneens zwarte woelrat of waterrat. Ook op Urk zouden ze ontbreken.

B ruine $\mathrm{R}$ at (Rattus norvegicus Berk.).

In 1942 werd een ex. waargenomen op kavel $R$ Ior, aan de rand van de polder, en een op de noordpunt van Schokland (FEEKES). In I943 wordt de soort reeds opgemerkt op talrijke plaatsen in het oostelijk deel van de polder, tot zelfs op G 106 (Dorp Emmeloord). Materiaal is afkomstig van $\mathrm{P} 28$, Aug. 1943; vier ex. van P 55, 56 en 65, April 1944; I $q$ van T 102, Juli 1944 (D. W. LANGeVELD).

Bij de enquête 1946 worden bruine ratten vermeld van vrijwel alle secties waar boerderijen zijn gevestigd. Behalve in de boerderijen zelf worden ze aangetroffen in schuren, stallen, stro- en graanbulten, bij kanalen en sloten.

Volgens Mörzer Bruyns waren bruine ratten in 1933 op Schokland in de omgeving van Middelbuurt aanwezig; in 1940 werden ze echter niet meer gevonden. Op Urk daarentegen komen ze volgens de bewoners veelvuldig voor op het haventerrein, ook vroeger voor de inpoldering.

$\mathrm{H}$ u is $\mathrm{m}$ u is (Mus musculus L.).

Zowel op Urk als op Schokland waren voor de droogmaking huismuizen te vinden. Van Schokland verkregen wij nog materiaal uit het voormalige Emmeloord in Sept. 1942 en Nov. I943. Voorts werden nog 4 ex. gevangen in Dec. 1942 op kavel $\mathrm{P}$ 105; 6 ex. in Mei 1943 op kavel $\mathrm{P} 49$ en 5 ex. in April I944 op kavel $Q$ II8.

Volgens de vragenlijst 1946 kwamen huismuizen overal voor waar bewo. ning was, in woonhuizen, boerderijen, schuren en in de kampen; verder buiten onder de graanklampen. Over het algemeen luiden de opgaven: enkele tot matig; veel of vrij veel worden er opgegeven voor de boerderijen op $K 70$, R 6, R 2I, N 5I, T II2.

Verwilderde kat (Felis catus L.).

Verwilderde katten worden overal aangetroffen in het dichte rietwoud, dat het westelijk deel van de po!der bedekt. De heer VAN LEeuwen zegt over deze rovers in het 7 e bericht over de broedvogels in de N. O. polder ${ }^{2}$ ) : „Het rietland herbergde een vrij talrijke kattenbevolking. Kater-pascha's met een harem zijn er gewoon en overal, tot in de verste uithoeken van de polder, vertellen hun sporen van de ondernomen zwerftochten." Maar ook in het cultuurgebied worden ze volgens de enquête 1946 overal gevonden, meestal slechts enkele; op $T$ I 12 werden echter vier stuks in het veld gezien en op $R 23$ een nest met 5 jongen aangetrof fen.

2) Limosa 20, 1947, p. I64. 
O t t e r (Lutra lutra L.).

De gegevens over otters zijn zeer schaars. Een werd er gezien in Mei I940 buitendijks nabij Ramspol (FEEKES). Vender werd eind Juni I946 een otter met drie jongen waargenomen zwemmende in de Nageler vaart bij Nagele, terwijl in Mei 1946 ottersporen werden aangetroffen op kavel C II.

\section{B unzing (Putorius putorius L.).}

Dit roofdier komt vrij algemeen voor, in 1943 werden er waargenomen op kavel R 39 en op Schokland (FEEKES). Volgens de cantinehouder op Urk zijn er zeer veel bunzings rondom Urk aanwezig (Juli I@Q46). De enquête I946 geeft de soort op voor hei gehele cultuurgebied, vooral onder graan-, hooi- en stroklampen te vinden.

We z e 1 (Mustela nivalis L.).

Wezels zijn zeer veelvuldig in de polder, zowel in het onontgonnen als in het in cultuur gebrachte gebied. Op Schokland zijn eveneens een groot aantal wezels; ook rondom Urk komen volgens de cantinehouder aldaar zeer veel wezels voor (1946). In Juli 1942 werd een $ᄋ$ verkregen van Schokland; in hetzelfde jaar werd een wezel gezien op kavel R 6 (FEEKES). Voor 1943 zijn waarnemingen genoteerd voor de kavels $\mathrm{R}_{74}, \mathrm{~S}_{46}, \mathrm{~T} 50, \mathrm{~N}_{40}, \mathrm{P}_{57}, \mathrm{E}_{34}$, B 9 en 31. '

He r m elij n (Mustela erminea L.).

De hermelijn is veel minder talrijk dan de wezel. In 1943 werden er waargenomen op kavel K 8, N. Schokland, A I2 en C 5 (Feekes). Ook de enquête 1946 verme!dt slechts enkele: op $\mathrm{K}$ I7, $\mathrm{R}$ 12 en $2 \mathrm{I}, \mathrm{T}$ I12, M I05, N 51, O 98, P 6 en 94.

Op Schokland is de hermelijn een enkele keer gezien; rondom Urk zouden ook hermelijnen voorkomen.

Vos (Vulpes vulpes L.).

Op 17 November 1948 werd voor het eerst een vos in het noorden van de polder gez:en.

K o $\mathrm{n}$ ij $\mathrm{n}$ (Oryctolagus cuniculus L.).

Het konijn houdt zich slechts hier en daar in de N. O. polder op. Volgens de cantinehouder te Urk (Juli I946) komen konijnen voor in de meerdijk van Lemmer tot aan de Rottendamse hoek (de bocht in de dijk halverwege LemmerUrk, bij kavel $\mathrm{B}$ 20). $\mathrm{Zij}$ maken holen in de dijk en zouden zelfs schadelijk zijn (?). Men meende, dat deze dieren afkomstig zouden zijn uit Gaasterland.

Voorts zouden nog enkele konijnen leven op een zandstortbult op kavel J 2, oost van Urk aan de Urkervaart. Ten dele zouden dit tamme konijnen zijn.

De enquête 1946 spreekt van: heel matig of een enkele, K I7 en M I39. 
$\mathrm{H}$ a a s (Lepus timidus L.).

In tegenstelling met het konijn treft men de haas overal zeer veelvuldig aan. De enquête 1946 geeft dan ook voor het gehele cultuurgebied de haas op als zeer algemeen. BoER schat het aantal op I per 6 ha.

In 1942 werden reeds hazen waargenomen op de kavels $\mathrm{K}$ I7, S 23 en 89, T 83 (FEEKES). In I943 breidt de soort zich uit over tal van andere secties, tot $\mathrm{J} 80$; in hetzelfde jaar werden op Schokland jonge haasjes gevangen door J. H. Muller.

$\mathrm{R}$ e e (Capreolus capreolus L.).

Een enkele maal dringen reeën in de polder door. In de zomer van 1943 werd een bok gezien zuid van Schokland, in hetzelfde jaar werd dit dier (?) door Duitsers geschoten nabij Schokkerhaven.

Ook in het westen van de polder zijn reeën waargenomen. In 1948 werden nabij de Rotterdamse Hoek sporen van een jong vastgesteld; mogelijk heeft de soort zich hier in het dichte rietland zelfs voortgeplant. De enquête I946 vermeldt een ex. van R 88; een gezien half Mei 1946 op N I2; een in het koolzaad. 